\title{
Many Sample Closet Medications Are Expired
}

\author{
Kari L. Evans, BS, and Steven R. Brown, MD
}

Introduction: Samples are widely used in office practice. It is not known how many sample medications are expired and therefore not useful to patients.

Methods: We inventoried 10 sample closets in primary care offices to quantify the number of expired medications.

Results: Of the 12,581 drug packages and boxes we inventoried in 10 sample closets, $14 \%$ of medications were expired. Sample closets varied widely in their organization; the range of expired medications in the 10 closets was $0 \%$ to $28 \%$.

Conclusion: Many sample closet medications are expired, indicating a substantial amount of waste. (J Am Board Fam Med 2012;25:394-395.)

Keywords: Drug Industry, Marketing, Physicians' Practice Patterns, Quality of Health Care, Sample Closet

The use of drug samples in office practice is widespread. In 2004, the retail value of sample medications was $\$ 16$ billion in the United States. ${ }^{1}$ In a 2009 survey, $80 \%$ of cardiologists, $70 \%$ of family physicians, and $67 \%$ of internists reported receiving drug samples. ${ }^{2}$ One study showed that sample medications are used in $20 \%$ of office encounters. ${ }^{3}$ Patients often expect samples. ${ }^{1}$ There is ample evidence, however, that the use of drug samples does not help patients. Sample medicines are often used personally by physicians and staff, lead to nonrational prescribing, and actually increase patient drug costs. ${ }^{1}$ In addition, sample medications are more likely to be used by wealthy and insured patients and may contribute to inferior care. ${ }^{1}$

Expired sample medications may also be a significant problem. The contents of sample closets, including expired medications, have not been studied in depth in the United States. Estimates from a sample inventory in Australia indicate that $6 \%$ of sample medications may be expired. ${ }^{4}$ The objective of our study was to inventory sample closets in local

This article was externally peer reviewed.

Submitted 13 August 2011; revised 18 October 2011; accepted 25 October 2011.

From the University of Arizona College of Medicine, Phoenix (KLE), and the Banner Good Samaritan Family Medicine Residency, Phoenix, AZ (SRB).

Funding: none.

Conflict of interest: none declared.

Corresponding author: Steven R. Brown, MD, 1300 N. 12th Street, Suite 605, Phoenix, AZ 85006 (E-mail: steven.brown@bannerhealth.com). family practice and general internal medicine offices to describe sample inventories and quantify the number of expired medicines.

\section{Methods}

In this cross-sectional study, we inventoried the drug closets of a convenience sample of 10 clinics in the Phoenix metropolitan area. The clinics were diverse; we inventoried the closets of 7 family medicine offices and 3 general internal medicine offices; of the 10, 6 were group practices, 4 were solo practices, and 5 were hospital-affiliated and 5 were private practices. Each closet was inventoried on a single day. We obtained informed consent from each office, and the University of Arizona institutional review board exempted our study from review. We recorded the drug name, quantity, dosage, and expiration date of all sample medications in each closet.

\section{Results}

The results of our inventory of 10 sample closets, including number of total samples and expired medications, are shown in Table 1 . The number of samples, the organization of the closets, and the number of expired medications was highly variable between practices. Two closets had no expired medications on the day we inventoried. 
Table 1. Results of Inventory of Ten Sample Closets in Phoenix Family Medicine and Internal Medicine offices

\begin{tabular}{lcccc}
\hline & Mean & Median & Range & $\begin{array}{c}\text { Total for } \\
10 \text { Closets }\end{array}$ \\
\hline $\begin{array}{l}\text { Sample boxes/packages } \\
\text { in closet (n) }\end{array}$ & 1258 & 1114 & $83-2850$ & 12,581 \\
$\begin{array}{l}\text { Expired boxes/packages } \\
\text { in closet (n) }\end{array}$ & 170 & 96 & $0-796$ & 1698 \\
$\begin{array}{l}\text { Expired boxes/packages } \\
\text { (\% of total) }\end{array}$ & 10 & 8 & $0-28$ & 14 \\
\hline
\end{tabular}

\section{Discussion}

In this study, $14 \%$ of sample medications were expired. In offices that had few expired medications, we were unable to quantify the number of medicines removed before our inventory. It is likely that our tally underestimates medication waste because some practices dispose of medications on a regular basis.

We hypothesize that there are 2 main reasons sample closets contain substantial numbers of expired medications. First, the presence of expired medications may be because of the absence of a reliable inventory system in most practices. Indeed, in a qualitative study of 18 family practice offices, Backer and colleagues ${ }^{3}$ described a wide variety of sample closet organization systems from "an extraordinary and meticulously organized shelving system," to a closet that was an "overfilled, disorganized stack of shelves," where "staff spent vast amounts of time searching for the appropriate sample." Maintaining sample inventories according to accreditation body regulations requires significant staff or physician effort. ${ }^{3}$ Second, the supply of individual medications, provided by pharmaceutical representatives as part of a marketing effort, may not match well with medications physicians prefer to use in practice. ${ }^{5}$

Regardless of cause, expired samples are not useful to patients and are a waste of resources. Our findings extrapolate to an estimated $\$ 2.2$ billion of wasted samples annually in the United States. Expired sample medications are yet another reason the widespread use of sample medications in medical practice should be re-examined.

\section{References}

1. Chimonas S, Kassirer JP. No more free drug samples? PLoS Med 2009;6(5):e10000074.

2. Campbell EG, Rao SR, DesRoches CM, et al. Physician professionalism and changes in physician-industry relationships from 2004-2009. Arch Int Med 2010;170(20):1820-6.

3. Backer EL, Lebsack JA, Van Tonder RJ, Crabtree $\mathrm{BF}$. The value of pharmaceutical representative visits and medication samples in community-based family practices. J Fam Pract 2000;49(9):811-6.

4. Hall KB, Tett SE, Nissen LM. Perceptions of prescription medicine samples on prescribing by family physicians. Med Care 2006;44(4):383-7.

5. Spurling G, Kyle G. Is your sample cupboard relevant to your practice? Aust Fam Physician 2007; 36(3):187-8. 